\title{
EDITORIAL ORAL ANTICOAGULANTS: CHALLENGES IN PAKISTAN. DO WE HAVE A SOLUTION?
}

\author{
Tariq Ashraf ${ }^{1}$, Muhammad Ishaq ${ }^{1}$ \\ ${ }^{1}$ Karachi Institute of Heart Diseases, Karachi, Pakistan
}

The common public health problem in thromboembolic disorders (TED) are venous thromboembolism (VTE) and stroke caused by Atrial Fibrillation (AF). ${ }^{1}$

The main stay of treatment among oral anticoagulants are Vit $\mathrm{K}$ antagonist (VKAs) like warfarin and acenocoumarin, warfarin has been the most commonly used drug particularly in Pakistan. However now Non Vitamin K dependent oral anticoagulants (NOACs) such as dabigatrin, rivaroxaban and apixaban have come in to use. ${ }^{2}$ Till now VKAs are most extensively used in developing countries like India ${ }^{3} \&$ Pakistan because of their effects can easily be reversed, and they are safe in impaired renal function besides being cost effective. The problems encountered with VKAs relate to dietary patterns in the region resulting in drug interaction, over usage of non-steroidal antiinflammatory drugs (NSAIDs) and most important the lack of lab facilities to monitor international normalized ratio (INR), and finally the lack of awareness of target INR levels by physicians \& patients.

Oral anticoagulants are the main stay in the prevention of stroke in patients with valvular and non valvular Atrial Fibrillation. ${ }^{4}$

The preferred oral anticoagulants with mechanical heart valves and severe mitral stenosis are the VKAs while for others stroke risk stratification is done by CHADS2-VASC score. $^{5}$ If CHADS2VASC score is of 3 in non valvular AF NOACS can be initiated.

The main challenge for stroke prevention is in pregnant women with AF who have either mechanical valve or severe valvular disease (Mitral Valve disease) in adjusting VKAs dose.

Low molecular weight Heparin (LMWH) is considered to be safe option ${ }^{6}$ in first trimester and before delivery. The recommended dose of warfarin in women with or without mechanical valves is $\leq 5$ $\mathrm{mg} /$ day throughout pregnancy, however during the first trimester dose adjusted LMWH is given to avoid teratogenic effects. Warfarin is continued in second and third trimesters and I/V unfractionated Heparin / LMWH in the peripartum period. ${ }^{7}$

The gynecologists being primary care givers should be trained in this respect to avoid any kind of complications. Another problem is to bridge antithrombin therapy in VHD patient schedule for surgery. The clinicians deciding factor for temporary stoppage of VKAs therapy is the type of heart valve prosthesis. ${ }^{8}$ Surgeon and anesthetist posted in rural health center in Pakistan should be provided management guidelines in the form of small printed cards in simple language. Knowledge of management of prosthetic valve complication ${ }^{9}$ and stroke management ${ }^{10}$ needs to be addressed especially in public hospitals.

In conclusion vitamin $\mathrm{K}$ antagonists such as warfarin is most commonly used in the Pakistan for valid reasons as mentioned. Awareness of PT/INR level to a therapeutic range to be made to patients and physicians by establishing anticoagulation clinics in all public hospitals throughout the country. NOACs to be initiated with appropriate use of CHADS2-VASC score with their appropriate indication and contraindication. Information leaflets on Anticogulation benefits, complications and interactions should be provided in local languages to the patients and they should keep a record of their INR values. Efforts should be made by various agencies in particular Ministry of NHS TO ensure uninterrupted availability of anticoagulants and cheap lab tests.

Although international evidence based guidelines do exist, they do not address specific goals required by ours patients. To enhance knowledge of our clinician regarding Vit K antagonist and NOACS its important to set local guidelines for various casebased scenarios.

Conflict of interest: Authors declared no conflict of interest.

\section{REFERENCES}

1. Amin A, Marrs JC. Direct oral anticoagulants for the management of thromboembolic disorders: the importance of adherence and persistence in achieving beneficial outcomes. Clin Appl Thromb Hemost. 2016;22(7):605-16.

2. Mekaj YH, Mekaj AY, Duci SB, Miftari EI. New oral anticoagulants: their advantages and disadvantages compared with vitamin $\mathrm{K}$ antagonists in the prevention and treatment of patients with thromboembolic events. Ther Clin Risk Manag. 2015;11:967.

3. Menon A, Thomas J, Ichaporia NR, Sahoo PK, Unni TG. Oral anticoagulation therapy: current challenges in Indian scenario. Int J Adv Med 2020;7:1044-52.

4. Asinger RW, Shroff GR, Simegn MA, Herzog CA. Anticoagulation for Nonvalvular atrial fibrillation: influence of epidemiologic trends and clinical practice patterns on risk 
stratification and net clinical benefit. Circ Cardiovasc Qual Outcom. 2017;10(9):e003669.

5. Alshawabkeh L, Economy KE, Valente AM. Anticoagulation during pregnancy: evolving strategies with a focus on mechanical valves. J Am Coll Cardiol. 2016;68(16):1804-13.

6. Kirchhof P, Benussi S, Kotecha D, Ahlsson A, Atar D, Casadei B, et al. 2016 ESC Guidelines for the management of atrial fibrillation developed in collaboration with EACTS. Eur Heart J. 2016;50(5):e1-88

7. Nishimura RA, Otto CM, Bonow RO, Carabello BA, Erwin JP, Fleisher LA, et al. 2017 AHA/ACC focused update of the 2014 AHA/ACC guideline for the management of patients with valvular heart disease: a report of the American College of Cardiology/American Heart Association Task Force on Clinical Practice Guidelines. J Am Coll Cardiol. 2017;70(2):252-89.
8. Saksena D, Muralidharan S, Mishra YK, Kanhere V, Mohanty $\mathrm{BB}$, Srivastava CP, et al. Anticoagulation Management in Patients with Valve Replacement. J Assoc Physicians India. 2018;66(1):59-74.

9. Powers WJ, Rabinstein AA, Ackerson T, Adeoye OM, Bambakidis NC, Becker K, et al. 2018 guidelines for the early management of patients with acute ischemic stroke: a guideline for healthcare professionals from the American Heart Association/American Stroke Association. Stroke. 2018;49(3): $46-99$

10. Morgenstern LB, Hemphill III JC, Anderson C, Becker K, Broderick JP, Connolly Jr ES, et al. Guidelines for the management of spontaneous intracerebral hemorrhage: a guideline for healthcare professionals from the American Heart Association/American Stroke Association. Stroke. 2010;41(9):2108-29.

Citation: Ashraf T, Ishaq M. Oral anticoagulants: Challenges in Pakistan. Do we have a solution?. Pak Heart J. 2021;54(02):124-125. DOI: https://doi.org/10.47144/phj.v54i2.2085

Address for Correspondence:

Dr. Tariq Ashraf, Karachi Institute of Heart Diseases, Karachi, Pakistan

Email: tariqash45@gmail.com 